\title{
Um professor do sul viaja para o norte: olhares sobre o ensino e a circulação de livros didáticos de História*
}

\begin{abstract}
Alexandra Lima da Silva ${ }^{1}$
Resumo: A partir da análise dos escritos de viagem do historiador e professor Rocha Pombo, busca-se problematizar os aspectos referentes à circulação de livros didáticos história e sua relação com o ensino nas décadas iniciais do século XX. Defende-se que o relato de Rocha Pombo pelo Brasil afora permite em muita medida, vislumbrar a existência de diferentes experiências de instrução pelo país evidenciando a circulação de livros didáticos e de diferentes práticas e concepções de educação no período, para além da esfera da capital tida como lócus intelectual e vitrine do progresso e da modernidade.

Palavras-chave: Rocha Pombo; Viagem; Livros didáticos
\end{abstract}

\begin{abstract}
From the analysis of the travel writings of historian and professor Rocha Pombo, seeks to discuss aspects related to the movement of history books and their relationship with the school in the early decades of the twentieth century. It is argued that the report Rocha Pombo throughout Brazil allows in great measure, to glimpse the existence of different experiences of education across the country, showing the movement of textbooks and different practices and conceptions of education in the period, beyond the sphere of taken as a locus intellectual capital and showcase the progress and modernity.

Keywords: Rocha Pombo; Travel; Textbooks
\end{abstract}

Compreender os olhares traçados por Rocha Pombo em relação à circulação de livros didáticos e ao ensino de História na viagem empreendida ao Norte do Brasil nos idos de 1917 é o horizonte deste trabalho. O relato do visto e vivido pelo andarilho foi registrado e publicado sob o título de Notas de Viagem, livro editado por Benjamin de Águila em 1918. A análise da escrita de viagem de um professor de história, por sua vez, permite mapear a comunhão em uma única obra, dos vários temas e interesses deste sujeito ao longo de sua trajetória. Rocha Pombo embarcara para conhecer as gentes, paisagens e histórias de um Brasil “interior" tão familiar e exótico ao mesmo tempo. Neste sentido, quais as motivações de Rocha Pombo, historiador, professor, jornalista, político, também enquanto viajante?

\footnotetext{
*Artigo recebido em 04 de Outubro de 2012, e aprovado em 10 de janeiro de 2013.

1 Professora Adjunta do Departamento de História e do Programa de Pós-Graduação em História da Universidade Federal de Mato Grosso. Bacharel, licenciada e mestre em História Social pela Universidade Federal Fluminense (UFF). Doutora em Educação pela Universidade do Estado do Rio de Janeiro (UERJ), com período de bolsa sanduíche financiada pela CAPES na Universidad de Alcalá. A pesquisa que originou o artigo contou com bolsa nota 10 da FAPERJ. E-mail: alexandralima1075@gmail.com 
Percorrendo os Estados do Espírito Santo, Sergipe, Alagoas, Paraíba, Rio Grande do Norte, Maranhão e Amazonas, realizou muitos encontros com autoridades locais, estabelecendo contatos que em muita medida, possibilitaram visitas às instituições de ensino, sendo recorrentes as temáticas: Instrução Pública; Escola Normal; Sanatórios e Escolas de Higiene; Asilo de Mendicidade; Orfanatos; Instrução Popular, dentre outros. Defendia que a instrução pública era uma das questões que mais deveria preocupar os governos, em todos os Estados, não somente no norte do país. Além disso, o relato de Rocha Pombo pelo Brasil afora permite, em muita medida, vislumbrar a existência de diferentes experiências de instrução pelo país, evidenciando a circulação de livros didáticos e de diferentes práticas de educação no período, para além da esfera da capital federal, tida como lócus intelectual e vitrine do progresso e da modernidade.

Nascido em 1857, na cidade de Morretes, interior do atual estado do Paraná, sul do Brasil, José Francisco da Rocha Pombo, ainda muito jovem, ingressou no magistério das primeiras letras e no exercício da escrita em periódicos, publicando artigos relacionados à instrução. Mudou-se para o Rio de Janeiro, então capital da República em 1897, onde, a partir de então, passa a frequentar os círculos intelectuais da cidade, em esforços diversos para sobreviver e se estabelecer no campo intelectual.

Foi poeta, historiador, professor do Colégio Pedro II, da Escola Normal, membro do Instituto Histórico e Geográfico (membro efetivo e honorário) e jornalista. Morreu aos 75 anos, quando acabara de ser eleito para a Academia Brasileira de Letras, sem tomar posse. Em relação aos impressos publicados de sua autoria, é possível apreender que escreveu contos, romances, poesia, livros de história, ensaios, dicionários, livros didáticos. Dentre os diferentes trabalhos acadêmicos sobre Rocha Pombo, verificam-se diferentes discursos e perspectivas de análise sobre o mesmo, conforme salienta Maria Bega:

\begin{abstract}
Rocha Pombo é uma personagem da história paranaense e brasileira que pode ser abordada em diversas facetas: jornalista, político, historiador oficial da República Velha, deputado provincial pelo Partido Conservador e mais tarde deputado federal pelo Paraná, filólogo e professor. Foi um romancista com extensa produção e com uma das poucas obras de prosa de ficção simbolista - No Hospício - publicada em 1905, bem como com incursões no ideário socialista e reformador social (BEGA, 2001, p. 157).
\end{abstract}

Negligenciada em grande parte dos estudos sobre o paranaense, a análise da escrita de viagem do intelectual paranaense, por sua vez, permite mapear a comunhão em uma única obra, dos vários temas e interesses deste sujeito ao longo de sua trajetória. O que um professor de história do sul observou e registrou a respeito do norte? 
Os relatos de Rocha Pombo pelo Brasil afora evidenciam a preocupação com a circulação e usos de livros didáticos, o que possibilita esboçar indícios sobre a circulação de livros e impressos em falas como esta, onde em visita ao Instituto Rosa Nina, no estado do Maranhão, afirmava que "não me lembro bem se ali encontramos, como em outras capitais, as cartas de Weiszflog ensino intuitivo" (POMBO, 1918, p. 128).

Outros trechos reforçam o argumento favorável ao interesse do viajante pelos livros didáticos, como na ocasião em que visitou o grupo escolar Barão de Maroim, dirigido pelo Dr. Mario Menezes, onde "vi as coleções Weiszflog para o ensino intuitivo" (Ibidem, p. 66). Ou ainda: "quando fui despedir-me do Dr. Matta, quem me veio receber no jardim, e muito ancho de alegria, foi o pequeno Arnaldo, dizendo-me logo que tinha lido já o Nossa Pátria, e abraçando-me carinhoso" (Ibidem, p. 206). Pode-se aferir que os usos dos livros didáticos não se limitavam ao ambiente da escola ou sala de aula, pois a leitura do menino Arnaldo parece ter sido no ambiente familiar, uma vez que Rocha Pombo visitara a casa e não a escola da criança. Ademais, interrogo: por que o viajante buscava e evidenciava apenas os livros da editora Weiszflog? Não teria observado livros de outros autores e editores?

A ênfase nos livros da recém-criada Weiszflog pode ser uma estratégia ${ }^{2}$ no competitivo mercado editorial, conforme também salientado por Fernanda Lucchesi, para a qual, “a Cia. havia entrado no mercado competitivo dos livros didáticos apenas em 1916. Assim, parece haver uma grande mobilização por parte da Melhoramentos para uma inserção vantajosa nesse mercado" (LUCCHESI, 2004, p. 102).

A escolha de Rocha Pombo parece ancorar-se na tentativa de conferir visibilidade à recém-lançada editora, bem como aos livros editados pela mesma, sendo a obra Nossa Pátria, e o próprio autor, Rocha Pombo, um dos investimentos da referida editora. Assim, a própria viagem pode ser pensada enquanto uma estratégia editorial no sentido de, não somente verificar a recepção e circulação dos impressos, como também, tornar mais conhecidos os seus autores. Ademais, uma estratégia da referida editora foi a realização de viagens pelo país, a fim de promover os livros por ela publicados. Neste sentido, José Alves Dias, considerado

\footnotetext{
${ }^{2}$ Nesse ponto, busco auxílio no entendimento da noção de estratégia, conforme proposto por Michel de Certeau, em que o autor francês chama de estratégia "o cálculo (ou a manipulação) das relações de forças que se torna possível a partir do momento em que um sujeito de querer e poder (uma empresa, um exército, uma cidade, uma instituição científica) pode ser isolado", onde se postula "um lugar suscetível de ser circunscrito como algo próprio e ser a base de onde se podem gerir as relações com uma exterioridade de alvos ou ameaças (os clientes ou concorrentes, os inimigos, o campo em torno da cidade, os objetivos e objetos da pesquisa etc)". Cf: CERTEAU, Micheal de. A invenção do cotidiano. Artes de fazer. Petrópolis, RJ: Vozes, 1994. ., 1994, p. 99
} 
"um auxiliar prestimoso," entrou para a editora em 1912, prestando diferentes serviços para a mesma, dentre os quais "viajava pelo Brasil fazendo a propaganda dos livros da Cia nos estados e estabelecendo relações com a elite intelectual dos lugares por que passava. É ele, por sinal, quem apresenta Pombo aos Weizsflog” (LUCCHESI, Idem).

O livro Nossa pátria. Narração dos fatos da História do Brasil através da sua evolução com muitas gravuras explicativas, escrito por Rocha Pombo e editado pela Weiszflog \& Irmãos chama atenção inicialmente pelas inúmeras reedições. Da primeira, em 1917, à última, em 1970, foram 88 edições e cerca de 452.000 exemplares impressos, o que demonstra a extensa duração no uso de um livro didático, que atravessava gerações e gerações, sem perder a aceitação do público e o interesse da editora em reeditá-lo.

Este livro apresenta muitas características interessantes. Seu formato é pequeno, in- $8^{\circ}$, assim como a maioria dos livros destinados ao ensino primário, tendo ao todo, 160 páginas, com textos leves e permeados por muitas gravuras, que fazem parte do corpo do texto, auxiliando as exposições do autor. A linguagem é simples, através da qual o autor parece tentar estabelecer uma conversa ou diálogo com o leitor, utilizando para tanto, referências e exemplos da atualidade, em contraponto com a vida nos tempos da colônia, vista como mais difícil e trabalhosa.

A utilização das gravuras neste livro não apenas serve como mera ilustração, mas enquanto parte de um método, acompanhando a exposição do autor, sendo "justamente, um dos diferenciais que a editora buscava era a riqueza e qualidade das imagens que ilustravam seus livros, já que tal recurso constituía-se em 'novidade' pedagógica” (LUCCHESI, Op. Cit., p. 102). A partir das gravuras, fotografias e quadros de pintores como Victor Meirelles, Benedito Calixto, reforça-se o que está sendo dito, num sentido de imprimir maior "veracidade" ou mesmo de convencimento pelo uso de "provas" compreensíveis ao leitor, principalmente aquelas visuais.

Através da fala do próprio autor ${ }^{3}$, notamos que o livro não se destinava apenas para uso das crianças escolares, como também, aos "homens simples do povo", o que demonstra o direcionamento e expectativa de usos do livro didático pelos populares, frequentadores ou não

\footnotetext{
${ }^{3}$ Neste sentido, temos aqui, um tipo de protocolos de leitura, conforme salientado por Chartier, em que o autor indica como o texto seria apreendido pelo "leitor ideal". Entretanto, deve-se considerar, para além das expectativas do autor, "o que se produz na própria matéria tipográfica, em geral de responsabilidade do editor, de modo a favorecer certa extensão da leitura e a caracterizar o seu "leitor ideal", que não precisa assemelhar-se àquele originalmente suposto pelo autor". (PÉCARA, Alcir. "Introdução". In: CHARTIER, Roger. (org). Práticas de leitura. São Paulo: Estação da Liberdade, 2001). 
dos bancos escolares: "Este livrinho é feito para a inteligência das crianças e dos homens simples do povo" (POMBO, 1917, p.1).

Neste sentido, estudos têm indicado a importância de se refletir sobre a possibilidade de uma ampliação e diversificação do público leitor de um modo geral, extrapolando as instituições de ensino formais da época e também a esfera da capital federal, indicando com isto o desenvolvimento de diferentes modos e usos da leitura já partir do século XIX, concebendo os livros didáticos para além do universo escolar, incluindo, assim, os possíveis usos realizados pelas camadas populares, como por exemplo, alunos de cursos noturnos, leitores autodidatas, o que se evidencia nas intenções de alguns autores e editores que buscavam produzir livros acessíveis também à "gente comum” (SILVA, 2008, p.50).

Tal movimento de ampliação do público leitor foi estudado por Martyn Lyons, para o qual, o público leitor do mundo ocidental se alfabetizou massivamente no século XIX, sendo importantes elementos nesse processo, a ampliação da educação primária, a redução da jornada de trabalho, o que propiciou mais tempo livre para a leitura e a oferta de livros mais acessíveis a todos os bolsos, Assim, o editores tiveram papel fundamental, pois exploravam plenamente as novas oportunidades, produzindo publicações baratas para serem entregues a um público mais amplo, no qual se incluíam mulheres, crianças e trabalhadores (LYONS , 1998).

Além de escrever um livro didático com a intenção de atingir diferentes públicos (diferentes faixas etárias e usos), a viagem de Rocha Pombo ao norte do Brasil em 1917 pode ter contribuído para que, posteriormente, os livros do intelectual paranaense tivessem ampla circulação pelo território nacional, como podemos verificar nas indicações do Nossa Pátria: “Aprovado oficialmente nos Estados de São Paulo, Santa Catarina, Sergipe, Maranhão e adotada no ensino desses Estados e dos de Paraná, Bahia e Rio Grande do Norte" (POMBO, 1917, p.1), sendo que muitos destes estados compuseram a rota do viajante em 1917. Ainda com relação ao investimento na ampliação do público leitor, as diversas estratégias das editoras foram fundamentais para que os livros cada vez mais circulassem pelo país. A Livraria Francisco Alves, por exemplo, divulgava outros endereços pelo Brasil afora onde se poderiam comprar os livros por ela editados:

Viúva Oliveri, no Estado da Bahia; João Walfredo de Medeiros, em Pernambuco; Joaquim José de Oliveira e C, no Ceará; $M F$ da Silva e C, no Pará; Antonio Pereira Ramos de Almeida e C, no Maranhão; Joaquim Alves Leite Sucessor, em Porto Alegre; Carlos Pinto e C, em Pelotas; Joaquim 
Dolivanes Nunes, em São Paulo; Rodrigo Antonio Pereira, em Juiz de Fora; Manuel Tomas Teixeira, em Ouro Preto; José Marques Nogueira Guerra, em Diamantina. ${ }^{4}$

A Companhia Melhoramentos, que também publicou outros livros de Rocha Pombo, teria total liberdade para modificar a composição do livro nos seus vários aspectos, como formato, ilustrações, grafia, entre outros, o que ajuda a compreender as sucessivas reedições que tal obra teve por esta editora: “Autorizo a Companhia Melhoramentos de São Paulo a usar na composição dos compêndios que para ela tenha escrito, e estou escrevendo, a grafia que lhe convier". Rocha Pombo esclarece que através da leitura de seu "livrinho", aqueles que necessitavam "amar a pátria" conheceriam melhor "nossa história", que seria repleta de sacrifícios e exemplos de heroísmo, feitos estes dos quais devemos nos orgulhar e segui-los, para caminharmos rumo ao progresso e ao desenvolvimento. Este seria "o sentido da história", pois: "São essas coisas que firmam nossa existência moral. Fizeram de grande os nossos antepassados. Equivale a tornar o compromisso de continuar na história" (POMBO, 1917, p.2).

Há também no referido livro didático, análises sobre a instrução no Brasil desde o período colonial, onde nas vilas, "eram raros os homens que sabiam ler e escrever. Não havia escolas. Quando muito, havia o que se chamava - mestres pagos- isto é, pessoas que ensinavam a ler, cobrando alguns vinténs por mês de cada aluno" (Ibidem, p.49). Para Rocha Pombo, somente a partir de D. Pedro II, começaram os esforços no que se refere à instrução do povo, onde passaram a existir escolas normais e ginásios em quase todas as capitais. Contudo, ressalta que existiriam poucas escolas primárias, “e o governo tratou de aumentar os números delas em todas as províncias, sendo que enquanto o governo fazia isso, criavam-se por toda parte sociedades de instrução, colégios particulares, clubes de leitura, onde todo mundo podia instruir-se" (Ibidem, p. 129).

Além dos colégios, argumenta em favor de outros espaços para o cultivo das letras, uma vez que, "em todas as capitais, os institutos históricos, os museus, os arquivos, fazem suas publicações, reunindo muita coisa sobre a natureza, sobre a nossa história, sobre os nossos homens notáveis" (Idem).

Por sua vez, Nossa Pátria fez parte de um movimento de investimento em leitura “para o povo e para as crianças". Em sua tese de doutorado, Patrícia Hansen defende que a

\footnotetext{
${ }^{4}$ Tais informações constam no "Anúncio da editora Alves \& Cia" na Revista do Ensino no ano de 1883. Apud: BITTENCOUT, Circe. Op.Cit., 1993, sem página. 
partir de finais do século XIX, importantes intelectuais brasileiros como Silvio Romero, Olavo Bilac, Coelho Netto, e outros, começaram a produzir livros de caráter cívico para o público infantil, relacionando a produção da literatura cívico-pedagógica à construção de um ideal de infância brasileira (HANSEN, 2007). Já Fernanda Lucchesi pontua que Contos Pátrios, escrito especialmente para as crianças, em parceria com Coelho Neto, publicado pela primeira vez em 1904, foi um dos mais lidos no gênero. Outro sucesso de público foi Através do Brasil, feito em parceria com Manuel Bonfim, em 1910, caracterizado por uma narrativa em torno das viagens de dois irmãos de 10 e 15 anos, que cruzam o território nacional, onde aprende-se sobre a história, costumes e gentes do Brasil (LUCCHESI, Op. Cit., p. 88).

Dentre os livros didáticos voltados para as classes elementares, escritos entre finais do século XIX e primeiras décadas do século XX, com perspectiva cívico pedagógica, muitos dos quais, destinados ao ensino da História do Brasil, destaco: Nossa pátria. Pequena História do Brasil Para uso das escolas primárias, de Mário Vasconcelos da Veiga Cabral (1923); Noções de Corografia do Brasil, para uso das classes primárias, de Joaquim Osório Duque-Estrada (1921); Lições de História do Brasil para uso das classes primárias, Joaquim Manuel de Macedo (1877); Lições de História do Brasil para uso das classes primárias, de Luís Queiroz de Matoso Maia (1905); Conheçamos Nossa pátria, Joaquim José de Meneses Vieira (1892); Através do Brasil, de Manuel Bonfim e Olavo Bilac (1910); Minha terra e minha gente, de Afrânio Peixoto (1915); Rudimentos de História do Brasil, autoria de João Ribeiro (1924); A história do Brasil ensinada pela biografia de seus heróis, de Sylvio Romero (1890); Homens e fatos da história pátria, estudos biográficos segundo a ordem estabelecida no programa das escolas primárias, de José Maria Velho da Silva (1895); Pequena história do Brasil, Francisco F Mendes Vianna e Euclides Mendes (1922); 24 pontos de História do Brasil segundo o programa oficial, por Amélia de Resende Martins (1923); Resumo da História do Brasil para uso das escolas primárias, por Maria Guilhermina Loureiro de Andrade (1894). Destes, elejo alguns, com ênfase naqueles que pude analisar em sua materialidade, para além da localização em catálogos ou anúncios, sobretudo para demarcar semelhanças e especificidades no período aludido.

A História do Brasil ensinada pela biografia de seus heróis foi publicada em 1890, pela então Livraria Clássica de Alves e Companhia, com 103 páginas, formato pequeno, in$8^{\circ}$. A capa dura do livro, como de costume na época, confere ênfase às "referências" do autor: Ensino cívico. A história do Brasil ensinada pela biografia de seus heróis, para uso das 
classes primárias, por Sylvio Romero. Professor do Instituto Nacional de Instrução Secundária. Com um prefácio e um vocabulário por João Ribeiro. Este livro traz como proposta metodológica o uso da biografia de "personagens ilustres" da história do Brasil, relacionando a vida "dos grandes homens" aos feitos e eventos históricos estudados, acompanhado de muitas gravuras em preto e branco dos "heróis nacionais". A maioria das imagens destaca os rostos das personagens, mas há também imagens da natureza local, paisagens, com a fauna e a flora do Brasil à época da chegada dos portugueses.

No prefácio assinado por João Ribeiro, destaca-se que o uso das biografias é crucial no ensino cívico, sobretudo por tratar-se dos "homens representativos" da pátria brasileira, reconstruindo a pátria pelos "patriotas", a história "anônima" pelo "documento autobiográfico", sintetizando a "espécie" pelos mais "exemplares indivíduos". Reforça-se com isto, a ideia de ensino através dos grandes exemplos, dos modelos de "perfeição" a serem atingidos. Por quem? Pelos alunos? Mestres? Que outros leitores eram visados e, de fato, poderiam ler tais livros?

Abaixo trago mais elementos para compreender tais proposições, em que os educadores aparecem como um dos grupos de leitores visados:

Sei que os educadores brasileiros estão um pouco prevenidos contra a ilusão da biografia na escola primária, onde aliás, ela deveria ser a primeira fase do estudo da história pela simples razão de todas as pedagogias possiveis de que o particular deva preceder ao geral. Mas aos educadores uma vez inocularam a mania da pretendida instrução cívica: eis o ponto de resistência (RIBEIRO, 1890).

Para João Ribeiro, apenas as apuradas qualidades de Sílvio Romero para captar a "geografia humana" do brasileiro, de modo a trabalhá-la em sala de aula a partir de seus excelentes métodos e erudição.

Assim, o livro de Sílvio Romero traz o uso das biografias associado às gravuras como "metodologias" de ensino para as classes primárias no momento, reforçando pelos grandes exemplos, os valores necessários à formação dos cidadãos.

Por sua vez, Joaquim Manuel de Macedo não escreveu lições apenas para o ensino secundário, tendo dedicado uma produção didática também ao ensino primário, que em muitos aspectos, segue as linhas metodológicas do primeiro livro Lições de História do Brasil, para uso dos alunos do Imperial Colégio de Pedro II (1861). 
Publicada pela Livraria Garnier, a nona edição lançada em 1905 trazia a seguinte "advertência" do editor, que preserva os planos do autor sem alterações:

Encarregado, pelo editor das lições, do Dr. Macedo, de completar este compêndio, tratei do mais, de respeitar o plano adotado pelo seu autor. Era isso principalmente o que me cumpria fazer, para não sacrificar o caráter de um livro que já nove edições sucessivas consagraram (MACEDO, 1905).

Nota-se também neste fragmento que a manutenção das características foi motivada em muita medida pela ótima aceitação que as edições do livro obtiveram junto ao mercado consumidor, por isto não as modificaram. Neste caso, ao contrário das justificativas que acompanham as alterações em função das indicações dos programas oficiais, como costumam argumentar as editoras, justifica-se a preservação da estrutura original em função da receptividade pelo público.

O livro possui 528 páginas, o que o autor justifica em função do uso de perguntas e quadros sinópticos incorporados ao livro, que lhe conferem um volume maior do que o esperado para uma "obra destinada ao estudo de meninos". O uso de perguntas e de resumos é utilizado pelo autor como recurso facilitador da memorização. Para Macedo, contudo, de nada adiantava um livro bem elaborado, preocupado em montar esquemas e metodologias para a sistematização dos conteúdos pelos alunos, se o professor não fosse capaz de utilizá-lo adequadamente em sala de aula:

Em trabalho deste gênero o método é sempre de importância essencial (...) Mas especialmente nas escolas de instrução primária, o professor é a alma do livro, e não há método que aproveite, se o professor não lhe dá vida, aplicando - o com paciência em consciência do ensino. (Prefácio do autor à primeira edição).

Assim como João Ribeiro, Macedo também atribuía à atuação do professor parte do sucesso e da aprendizagem do aluno, sendo o livro apenas uma espécie de "guia" para as lições. Por sua vez, retornando à obra de Rocha Pombo, Nossa Pátria representou "um novo tipo de compêndio, escrito na contraposição aos livros 'indigestos' de que reclamava Veríssimo" (LUCCHESI, Op. Cit., p. 85), tendo obtido grande êxito entre o público e o professorado de modo geral.

Já em Através do Brasil, Olavo Bilac e Manuel Bonfim narram a jornada educativa dos irmãos Carlos e Alfredo pelos diferentes estados do Brasil com o intuito de explorar as riquezas do Brasil e aguçar o olhar para dentro do próprio país. Para os autores, o livro deveria ser utilizado para auxiliar o trabalho do professor, além de fomentar nas crianças o 
gosto pela leitura, incentivar o conhecimento pelas gentes e paisagens do Brasil. Assim, nas palavras dos próprios autores:

\begin{abstract}
Além de servir de-oportunidade para que o professor possa realizar as suas lições, o livro de leitura deve conter em si mesmo uma grande lição. E acreditamos que isso se dá com o nosso trabalho. Estamos certos que a criança, com sua simples leitura, já lucrará alguma coisa: aprenderá a conhecer um pouco o Brasil; terá uma visão, a um tempo geral e concreta, da vida brasileira, -as suas gentes, os seus costumes, as suas paisagens, os seus aspectos distintivos. E por isso escolhemos como cenário principal as terras do São Francisco, -0 grande rio, essencialmente, unicamente brasileiro (BILAC \& BONFIM, 1931, p.2).
\end{abstract}

Na perspectiva de André Botellho, a uso didático da narrativa de viagem não seria uma novidade em Bilac e Bonfim, uma vez que desde o século XVIII, sobretudo a partir da obra Emílio, de Rousseau, as jornadas podem ser exploradas com um sentido instrutivo, pois “constitui oportunidade para o aprendizado histórico, geográfico, botânico e dos costumes dos lugares visitados"(BOTELHO, 2004, p.102). Ainda de acordo com André Botelho, a travessia dos irmãos Carlos e Alfredo pelo Brasil afora é mais do que um deslocamento espacial pelo território nacional, tendo representado "uma jornada educativa que se realiza na interação dos personagens - e dos leitores- com uma determinada realidade objetiva representada com intenção verossímil na narrativa como o próprio Brasil” (Ibidem, p.104).

Se no caso Através do Brasil, a viagem fictícia dos pequenos irmãos foi utilizada como linguagem para atingir o público infantil e os professores, a viagem de Rocha Pombo dentre outros aspectos, objetivava verificar a circulação dos livros didáticos do autor nos estados do norte, na busca por diferenciação e mesmo, demarcar um território frente os demais concorrentes do campo.

\title{
- Presença negra nos bancos escolares e questão racial
}

A preocupação com a necessidade da escolarização das crianças negras também ganhou destaque no relato de viagem de Rocha Pombo, que buscava evidenciar os outros sujeitos que posicionados em lugares sociais distintos, ansiavam por espaço e participação no mundo das letras e na própria ampliação dos direitos da cidadania. Neste sentido, é possível 


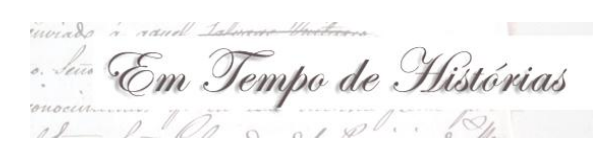

compreender o interesse de Rocha Pombo pela instrução de sujeitos como este aluno do Atheneu Sergipense:

Prendeu nossa atenção o aluno Anthenor Lyrio Coelho, pretinho, falando Francês, e já bem encaminhado no Latim. Ao despedir-me deste aluno, não pude excusar-me de dizer-lhe ao ouvido: "V pertence, meu filho, a uma outra raça que se sacrificou aqui por outra: essa outra agora lhe está pagando. Aproveite quanto puder, e há de ir longe"(POMBO, Op. Cit, p. 66).

Se por um lado, a presença de um menino negro prendeu a atenção do visitante, por outro lado, é um indício da escolarização cada vez maior, de crianças negras em diferentes regiões do país, conforme têm indicado estudos no âmbito da história da educação, após anos de invisibilidade da questão ${ }^{5}$. Conforme indica Surya Aaronovich Pombo de Barros, um dos caminhos possíveis para o estudo de tal questão podem ser, inclusive, as fontes de cunho autobiográfico, que trazem elementos para se pensar os distintos processos de escolarização e assim como na fala de Rocha Pombo, trazem à tona a presença negra na escola, que nem sempre era vista de forma otimista ou positiva.

Ao explorar o relato autobiográfico de Helena Morley, por exemplo, Surya de Barros evidencia o olhar receoso da normalista em ter que lecionar para crianças negras, lamentando, "que será de mim se for obrigada a largar a Escola, estudo, minhas colegas e tudo para ir ensinar a meninos pretos e burros no Rio Grande?”(MORLEY, 1998, p. 275). Ou em outro momento, quando o relato de Helena indica a existência de professores negros ${ }^{6}$, afirmando, “como se pode ser tão bom como o nosso professor Dr. Teodomiro! Depois meu pai ainda diz que gente escura não presta. Na Escola, pelo menos, os melhores é ele e Seu Artur Queiroga. Os brancos são crus de ruindade"(Ibidem, p. 8).

\footnotetext{
${ }^{5}$ Dentre os trabalhos que analisam a escolarização de crianças negras, destacam-se:

DEMARTINI, Zeila de Brito Fabri. “A escolarização da população negra na cidade de São Paulo nas primeiras décadas do século" in Revista da ANDE, n. 14, 1989; BARROS, Surya Aaronovich Pombo de. Negrinhos que por ahi andão: escolarização da população negra em São Paulo (1870-1920). São Paulo, Dissertação (Mestrado) - Faculdade de Educação, Universidade de São Paulo, 2005; FONSECA, Marcus Vinícius. Pretos, pardos, crioulos e cabras nas escolas mineiras do século XIX. São Paulo, Tese (Doutorado em Educação), 2007; VEIGA, Cynthia Greive. "Escola pública para os negros e os pobres no Brasil: uma invenção imperial". Rev. Bras. Educ. [online]. 2008, vol.13, n.39, pp. 502-516; GONÇALVES, Luiz Alberto Oliveira. "Negros e educação no Brasil.” In: LOPES, Eliane Maria Teixeira; FARIA FILHO, Luciano Mendes; VEIGA, Cynthia Greive (Orgs.). 500 anos de educação no Brasil. Belo Horizonte: Autêntica, 2000, pp. 325-346.

${ }^{6}$ A respeito da existência de professores negros, ver os estudos de: MULLER, Maria Lucia. "Professoras negras na Primeira República". Cadernos PENESB, Niterói: Intertexto, 1999; MULLER, Maria Lucia Rodrigues. A cor da escola. Imagens da Primeira República. Cuiabá: Entrelinhas/EdUFMT, 2008; D’ÁVILA, Jerry. Diploma de brancura: política social e racial no Brasil, 1917-1945. São Paulo: Editora UNESP, 2006.
} 
Por seu turno, ao relacionar a presença de um aluno negro nos bancos escolares aos sacrifícios da escravidão, o intelectual paranaense concebe o direito das populações afrodescentes à instrução formal como uma compensação pelos "bons serviços" prestados à nação nos tempos da escravidão, sendo estes considerados no livro didático Nossa Pátria, "trabalhadores, obedientes e muito espertos, tendo feito muito pelo progresso do nosso país".

Afirma ainda que os sofrimento e sacrifícios dos africanos escravizados no Brasil teriam sido recompensados, "pois hoje os descendentes daqueles pobres escravos hoje são iguais aos antigos senhores, e sem dúvida muito mais felizes do que os parentes que ficaram lá na África" (POMBO, Op. Cit., 1917, p. 32). Rocha Pombo defendia ainda que a composição étnica do brasileiro era fruto das três raças fundadoras, sendo o brasileiro o herdeiro do índio, "altivo", do africano, "amoroso", e do europeu, o "inteligente", construindo o que nos dias atuais os estudiosos denominam de mito ou fábula das três raças (Idem).

Os índios seriam aqueles que aqui já existiam antes da chegada do colonizador europeu, sendo estes vistos como "muito atrasados quanto à civilização. Viviam em grupos de famílias (tribus), mudando sempre de lugar para outro" (Idem). Além disso, seriam os índios muito afeitos a brigas e à guerra, o que era considerado um comportamento natural entre os ditos selvagens, uma vez que somente entre o homem civilizado, a razão seria utilizada, em detrimento da força. $\mathrm{O}$ dito homem civilizado resolveria tudo pelo direito e não pelas armas. Em função da dificuldade em transformar os índios em colonos, os portugueses teriam optado pelo africano. Rocha Pombo considerava em seu livro didático que "esta gente era também selvagem como os índios, e vivia lá quase como os índios viviam aqui” (Ibidem, p.29), sendo a principal diferença o fato de que os africanos não seriam livres como os índios, pois, estes, tinham os seus reis, "chamados sobas, que com eles eram muito cruéis, vendendo gente como se gado fosse" (Idem).

Para o intelectual paranaense, "o africano é preto por causa do clima da África, que é muito quente; mas é uma raça muito boa, principalmente de muito bom coração" (Idem), onde "quase todos, em vez de odiar, ficaram logo querendo bem aos senhores. Sobretudo as mulheres foram as grandes amigas das crianças". Outra visão defendida pelo autor de Nossa Pátria era a de que os africanos seriam naturalmente, "trabalhadores, obedientes e muito espertos, tendo feito muito pelo progresso do país" (Idem).

Ao dissertar sobre os quilombos, no capítulo XVII de Nossa Pátria, Rocha Pombo defende que as mulheres seriam aproveitadas no serviço doméstico, aprendendo tudo com 
mais facilidade, sendo preferidas às índias. Indo para as fazendas ou para os engenhos, os escravos passariam a viver como um rebanho, sob as rédeas do senhor, o que dificultava a aprendizagem da língua do branco, favorecendo a manutenção de quase todos os usos, costumes e festas da África. Avesso ao conflito, Rocha Pombo constrói uma visão suavizada da escravidão, sobretudo com afirmações como esta, em que "nem todos os senhores eram maus. Muitos tratavam até muito bem os escravos, dando-lhes descanso aos domingos, e considerando que se divertissem cantando as cantigas e dançando as danças usadas lá na pátria que nunca mais veriam" (POMBO, Op. Cit., 1917, p. 32).

Já os europeus são descritos como os colonizadores, aqueles responsáveis pela colonização e transformação do território em civilização, sendo a população do Brasil formada a partir das três raças: os índios, que já estavam aqui, os africanos, que vieram como escravos, e os europeus, que tomaram conta do país. Se, por um lado, a formação do brasileiro teria se dado pela junção de "três raças", nota-se que o "elemento africano" é associado de imediato ao escravo, ou seja, o que "pegou no pesado", por se o mais "propenso à escravidão" por suas origens culturais advindas da África. Além das falas do autor, o uso de imagens reforça os sentidos dos modos de vida do "negro africano no Brasil", que seria muito ligado às danças, festejos e ao trabalho "braçal".

\section{-Grupos escolares, instrução popular e projetos de intervenção social}

A instrução popular pode ser apontada como outra preocupação recorrente nas observações tecidas pelo viajante, sendo esta entendida como uma necessidade para a formação do povo brasileiro, onde, "não cessarei de dar testemunho, a instrução popular é objeto da preocupação e do esforço de todos os governos e de todas as populações" (POMBO, Op. Cit., 1918, p. 102). Para ele, uma das iniciativas mais importantes no sentido de atender às demandas da instrução popular seriam os grupos escolares, que se encontrariam já em todos os estados do norte, pois, “aliás, isto é comum em todos os estados do norte: não há uma só capital onde se não encontrem estabelecimentos dessa ordem, que já entraram, podese dizer, definitivamente no regime do ensino"(Idem). Ademais, a implantação dos grupos escolares difundiu-se pelo Brasil, compondo a política de muitos governadores dos estados. 
Assim, os grupos escolares teriam chegado ao Pará em 1899, em 1908 no Rio Grande do Norte, em Sergipe em 1911, na Paraíba em 1916 e no Piauí em 1920.

A instrução, existência e difusão de bons livros pelo país poderiam representar para um intelectual como Rocha Pombo, não apenas a difusão de suas ideias a um público escolar, mas uma aproximação entre o "povo" e os "homens de letras" do país para a superação do atraso, rumo ao progresso e ao desenvolvimento pela educação, em sentido amplo.

\section{Últimas considerações}

Ao término deste trabalho, concluo que a viagem de Rocha Pombo ao norte do Brasil teve uma estratégia editorial frente às demandas do mercado de livros didáticos em expansão. Ademais, o viajante do sul conheceu outras paisagens. Superou medos e angústias. Enfrentou a saudade da família. Ampliou redes. Tornou-se conhecido. Divulgou seus livros. Da viagem inspirou-se para outras escritas da História: Universal, da América, do Brasil, de São Paulo, do Rio Grande do Norte. Não mais um aventureiro! Escrevia agora com a autoridade da experiência que a travessia lhe proporcionara, em tempos nos quais, saboreou arquivos, visitou instituições diversas. Consultou livros, ouviu as gentes e histórias pelo Brasil afora.

O relato de Rocha Pombo pelo Brasil afora permite em muita medida, vislumbrar a existência de diferentes experiências de instrução pelo país, evidenciando a circulação de livros didáticos e de diferentes práticas e concepções de educação no período, para além da esfera da capital tida como lócus intelectual e vitrine do progresso e da modernidade. Defendo, com isto, a perspectiva de que a análise do registro e da prática da viagem em Rocha Pombo o circunscreve no movimento coletivo de diferentes sujeitos e debates a cerca da necessidade de projetos de educação para o "povo", na constituição de um país que se pretendia grande, encontrando na diversidade a constituição enquanto pátria para o progresso, unida do sul ao norte pelo caminho das letras e dos livros.

\section{Referências bibliográficas}

BARROS, Surya Aaronovich Pombo de. Negrinhos que por ahi andão: escolarização da população negra em São Paulo (1870-1920). São Paulo, Dissertação (Mestrado) - Faculdade de Educação, Universidade de São Paulo, 2005.

BEGA, Maria Tarcisa Silva. Sonho e invenção do Paraná: geração simbolista e a construção de identidade regional, Tese de Doutorado (Sociologia), USP, 2001.

BILAC, Olavo \& BONFIM, Manuel. Através do Brasil. Rio de Janeiro: Francisco Alves, 1931.

BITTENCOURT, Circe. Livro didático e conhecimento histórico: uma história do saber escolar. Tese (Doutorado)- Faculdade de Filosofia, Letras e Ciências Humanas da Universidade de São Paulo, São Paulo, 1993. 
BOTELHO, André. Aprendizado do Brasil. A nação em busca dos seus portadores sociais. Campinas: Ed Unicamp, 2002.

DEMARTINI, Zeila de Brito Fabri. “A escolarização da população negra na cidade de São Paulo nas primeiras décadas do século" in Revista da ANDE, n. 14, 1989.

D’ÁVILA, Jerry. Diploma de brancura: política social e racial no Brasil, 1917-1945. São Paulo: Editora UNESP, 2006.

FONSECA, Marcus Vinícius. Pretos, pardos, crioulos e cabras nas escolas mineiras do século XIX. São Paulo, Tese (Doutorado em Educação), 2007.

GONÇALVES, Luiz Alberto Oliveira. "Negros e educação no Brasil.” In: LOPES, Eliane Maria Teixeira; FARIA FILHO, Luciano Mendes; VEIGA, Cynthia Greive (Orgs.). 500 anos de educação no Brasil. Belo Horizonte: Autêntica, 2000, pp. 325-346.

HANSEN, Patrícia. Brasil, um país novo: literatura cívico-pedagógica e a construção de um ideal de infância brasileira na Primeira República. São Paulo, Tese (Doutorado em História Social), USP, 2007.

LYONS, Martyn. "Los nuevos lectores del siglo XIX: mujeres, niños, obreros.” In: CAVALLO, Gugliermo y CHARTIER, Roger. Historia de la lectura en el mundo occidental. Madrid: Taurus, 1998, pp. 473-517.

LUCCHESI, Fernanda. A história como ideal: reflexões sobre a obra de José Francisco da Rocha Pombo. Dissertação (Mestrado em Antropologia), Universidade de São Paulo, 2004.

MACEDO, Joaquim Manuel de. Lições de História do Brasil para uso das classes primárias. $9^{\text {a }}$ Edição. Rio de Janeiro: Francisco Alves, 1905.

MORLEY, Helena. Minha vida de menina. Cia das Letras, 1998.

MULLER, Maria Lucia. "Professoras negras na Primeira República". Cadernos PENESB, Niterói: Intertexto, 1999.

MULLER, Maria Lucia Rodrigues. A cor da escola. Imagens da Primeira República. Cuiabá: Entrelinhas/EdUFMT, 2008.

PÉCARA, Alcir. "Introdução". In: CHARTIER, Roger. (org). Práticas de leitura. São Paulo: Estação da Liberdade, 2001.

POMBO, José Francisco da Rocha. Notas de viagem. Norte do Brasil. Rio de Janeiro: Benjamin de Águila editor, 1918.

1917.

Nossa Pátria: narração dos fatos da História do Brasil através da sua evolução. São Paulo: Weiszflog,

RIBEIRO, João. "Prefácio". In: ROMERO, Sylvio. A História do Brasil ensinada pela biografia de seus heróis. Rio de Janeiro: Livraria Clássica de Alves e Companhia, 1890.

SILVA, Alexandra Lima da. Ensino e mercado editorial de livros didáticos de História do Brasil. Niterói, Dissertação (Mestrado em História), UFF, 2008.

VEIGA, Cynthia Greive. "Escola pública para os negros e os pobres no Brasil: uma invenção imperial". Rev. Bras. Educ. [online]. 2008, vol.13, n.39, pp. 502-516. 